\title{
Transnasal Percutaneous Endoscopic Gastrostomy (T-PEG): An Alternative Approach to Conventional PEG Placement
}

\author{
Anudeep KV $^{1} \quad$ Rakesh Kalapala ${ }^{1} \quad$ Santosh Darishetty ${ }^{2} \quad$ Thejesh Katamreddy $^{2} \quad$ D. N. Reddy ${ }^{1}$ \\ ${ }^{1}$ Department of Medical Gastroenterology, AIG Hospitals, \\ Hyderabad, Telangana, India \\ 2Department of Endoscopic Anesthesia, AIG Hospitals, Hyderabad, \\ Telangana, India \\ Address for correspondence Rakesh Kalapala, MD, DNB, \\ Department of Medical Gastroenterology,AIG ,Hospitals, \\ Mindspace Road, Gachibowli, Hyderabad, 500032, Telangana, India \\ (e-mail:drkalpala@gmail.com).
}

J Digest Endosc 2021;12:114-115.

\author{
Abstract \\ Keywords \\ - head and neck \\ malignancy \\ - percutaneous endo- \\ scopic gastrostomy \\ - T-PEG
}

Transnasal percutaneous endoscopic gastrostomy (T-PEG) is a novel endoscopic intervention for enteral nutrition. Peroral endoscopic gastrostomy is widely performed feeding procedure. However, it cannot be done in 4 to $7 \%$ of cases with head \& neck malignancies. T-PEG is a safe and viable alternative procedure in those patients. T-PEG can be performed in patients with head and neck malignancies, malignant oropharyngeal obstruction, and trismus where oral endoscopy is not feasible.

\section{Introduction}

A 55-year-old male presented with difficulty in swallowing and weight loss for 1 month. He was diagnosed to have carcinoma cervical esophagus 6 years ago and treated with definite chemoradiation. He was under palliative care for carcinoma base of tongue for the last 1 year. He has progressive dysphagia for 1 month and came to our center for feeding procedure. Carcinoma base of tongue causing obstruction precluded the use of oral gastroscope. Hence, he was planned for transnasal percutaneous endoscopic gastrostomy (T-PEG). However, this was not easy as patient breathing would be difficult with single nostril since oral cavity was compromised. Ventilation was secured with nasopharyngeal airway (-Fig. 1). Nasal endoscope was passed. Stomach was entered without much difficulty through larynx and esophagus. Transillumination was noted in anterior abdominal wall and finger indentation was noted in the distal body of stomach. At this point, skin incision of $1 \mathrm{~cm}$ was made using scalpel. Large bore needle with cannula was introduced into the stomach through this incision. Needle was removed keeping the cannula inside stomach. PEG wire was introduced into the stomach through

published online May 7, 2021
DOI https://doi.org/ $10.1055 / \mathrm{s}-0041-1731586$ ISSN 0976-5042 the cannula and was held with forceps and pulled through the nose. Figure of eight knot was made and adequately lubricated. 24-Fr cook PEG tube was placed in the stomach using pull through technique. Mild resistance was felt while pulling the internal bolster through nostril; however, there were no intraprocedural or postprocedural complications. Postoperatively he did not develop any fever, however, antibiotics were given for 5 days to prevent infection. PEG feeds were started next day and patient was discharged in stable condition (Supplementary Video 1; available in the online version).

Peroral endoscopic gastrostomy is the standard of care for patients requiring long-term enteral nutritional support. However, it is not feasible in 4 to $7 \%$ of head and neck cancer patients owing to underlying pathology. ${ }^{1} \mathrm{~T}-\mathrm{PEG}$ is a viable alternative for those patients. Counihan et al reported first successful T-PEG using a pull method in a patient with intermaxillary fixation. ${ }^{2}$ Other pragmatic indications include malignant oropharyngeal obstruction and trismus. There are three techniques of PEG tube insertion: pull, push, and introducer. Pull and push techniques are more popularized owing to low chance of dislodgement. (c) 2021. Society of Gastrointestinal Endoscopy of India.

This is an open access article published by Thieme under the terms of the Creative Commons Attribution-NonDerivative-NonCommercial-License, permitting copying and reproduction so long as the original work is given appropriate credit. Contents may not be used for commercial purposes, or adapted, remixed, transformed or built upon. (https://creativecommons.org/licenses/by-nc-nd/4.0/).

Thieme Medical and Scientific Publishers Pvt. Ltd. A-12, 2nd Floor, Sector 2, Noida-201301 UP, India 


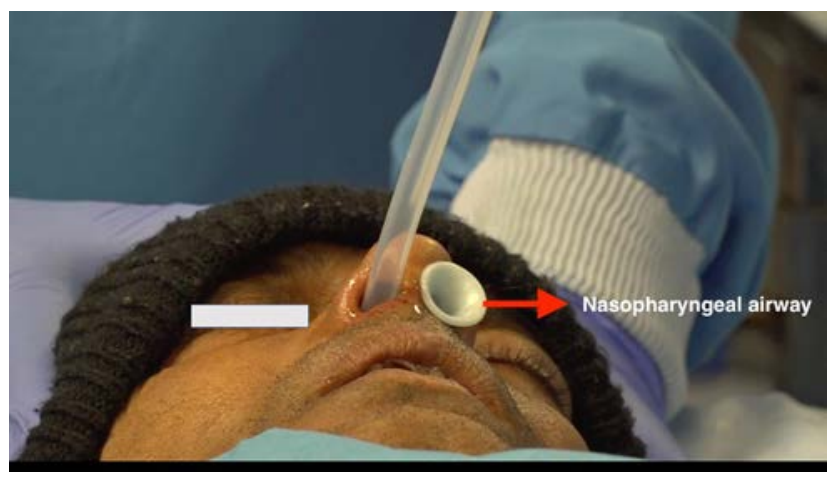

Fig. 1 Image showing nasopharyngeal airway in left nostril and PEG tube in the right nostril. PEG, percutaneous endoscopic gastrostomy.

Introducer technique has higher chance of bleeding and catheter dislodgement. ${ }^{3}$ Pseudomonas aeruginosa infection of stomal site has been reported in patients undergoing T-PEG. ${ }^{4}$ Securing ventilation with nasopharyngeal airway is of great importance as patient can breathe only through one nostril. A specific concern is the fear of tumoral seeding at the time of PEG placement. The risk of this adverse event is small and there have been no reports of tract seeding using the transnasal approach. The safety of T-PEG has been established and no significant differences between the transnasal and the transoral approach in regard to hemodynamics, success, or adverse events. There are studies on successful T-PEG placement, but this is the first report showing the intricate steps of procedure. ${ }^{5}$ To conclude, T-PEG is a safe and effective procedure, especially in patients where oral endoscopy is not feasible due to various reasons.

\section{Video 1}

Transnasal gastrostomy.Online content including video sequences viewable at: https://www.thieme-connect. com/products/ejournals/html/10.1055/s-0041-1731586

\section{Conflict of Interest}

None declared.

\section{References}

1 Zuercher BF, Grosjean P, Monnier P. Percutaneous endoscopic gastrostomy in head and neck cancer patients: indications, techniques, complications and results. Eur Arch Otorhinolaryngol 2011;268(4):623-629

2 Counihan T, Napolitano LM, Heard SO. Transnasal insertion of percutaneous endoscopic gastrostomy in a patient with intermaxillary fixation: case report. J Trauma 1996;41(3):530-532

3 Lee HS, Lim CH, Park EY, et al. Usefulness of the introducer method for percutaneous endoscopic gastrostomy using ultrathin transnasal endoscopy. Surg Endosc 2014;28(2):603-606

4 Lin LF. Transnasal versus conventional peroral insertion of percutaneous endoscopic gastrostomy using pull method. Adv Dig Med 2016;30:56-60

5 Nevah MI, Lamberth JR, Dekovich AA. Transnasal PEG tube placement in patients with head and neck cancer. Gastrointest Endosc 2014;79(4):599-604 